\title{
Covid-19 Pandemi Sürecinde Oluşturulan Capslerin Analizi
}

\author{
DOI: $10.26466 /$ opus.853718
}

$*$

\author{
Onur Bayrakçı * \\ * Dr.Öğretim Üyesi, Bandırma Onyedi Eylül Üniversitesi SHMYO Bandırma/Türkiye \\ E-Posta: onurbayrakci@outlook.com \\ ORCID: $\quad 0000-0001-5300-8389$
}

\section{Öz}

Dünyada ve Türkiye'de COVID-19 salgınının etkisi toplumlarm tüm alanlarında derin bir şekilde hissedilmiştir. COVID-19 salgınıyla mücadeleye ilişkin hükümetin Mart 2020'den bu yana başlatılan tedbirlerinin sonucu olarak sosyal yaşamı da önemli derecede etkilemiştir. Hükümet ve hükümetler tarafindan uygulanan kısmi tecrit (sokağa çıkma yasağı) gerek Türkiye'de gerekse dünya çapinda deoletleri ve hükümetleri zor kararlarla karşı karşıya kalmasına neden olmuştur. Sosyalleşmenin daraldığ̊ ve aile ve iş hayatıyla kısıtlandı̆̆ı bu salgın döneminde pandeminin yansımaları mizahta karşıllğııı bulmuştur. Mizah bir tarftan güldürürken diğer taraftan da düşünüdüren bir sanattır. Caps te bu sanat içinde web 2.0'ın kullanımı sonrası ortaya çıkan yeni bir mizahi alandır. Caps fotoğraflar üzerine metin eklenerek güldüren ve ayn zamanda düşündüren bir iletişim metodudur. Pandemi döneminde de önemli oranda sosyal medya üzerindne yoğun bir caps paylaşımı yapılmıştır. Sosyal medya üzerinden yapılan bu caps paylaşımları Fransız dil bilimci Ronald Bartes'in göstergebilimsel analizi yöntemiyle incelenmiştir. Bu çalışmanın amacı pandeminin neden olduğu sorunların capsler üzerinden analizini kapsamaktadır.

Anahtar Kelimeler: Pandemi, caps, mizah, gülme, göstergebilim 
ISSN:2528-9527

E-ISSN : 2528-9535

YIl Year: 11

Cilt Volume: 17

Sayı Issue :Pandemi Özel Sayısı

Nisan April 2021

\title{
Analysis of Caps Created During The Covid-19 Pandemic
}

*

\begin{abstract}
The impact of the epidemic Covidien-19 in the world and Turkey has been felt in all areas of society in a profound way. As a result of the government's measures to combat the COVID-19 pandemic, initiated since March 2020, it has also significantly affected social life. Partial isolation imposed by the government and (lock down) should both states and governments worldwide in Turkey has caused to be faced with difficult decisions. In this epidemic period, where socialization was narrowed and restricted by family and business life, the reflections of the pandemic found its answers in humor. Humor is an art that makes you laugh from one side and think from the other side. Caps is a new humorous field that emerged after the use of web 2.0 within this art. Caps is a communication method that makes you laugh and also makes you think by adding text on photos. During the pandemic period, intense caps were shared on social media to a significant extent. These caps posts made on social media were analyzed with the method of semiotic analysis of French linguist Ronald Bartes. The aim of this study is to analyze the problems caused by the pandemic through capses.
\end{abstract}

Keywords: Pandemic, caps, humor, laughter, semiotics 


\section{Giriş}

2020 yılının hemen başında Çin'in Wuhan kentinde patlak veren Covid- 19 pandemisi tüm dünyada bomba etkisi yaratmış ve her şey tepe takla olmuştur. Ekonominin yanı sıra günlük rutinlerimiz de pandemiyle beraber değişme uğramıştır. Alış veriş ilişkilerimizden selamlaşmaya, iş ilişkilerinden sanatsal faaliyetlere kadar her şey yapı bozuma uğratılmış ve yeni olana uyum bir sürü soruna gündemimize almıştır. Pandemi sadece ilişkileri değiştirmekle kalmamış bununla birlikte kısıtlamaları da getirmiştir. Kısıtlamaların en önemlileri ise sosyalleşmenin vücut bulduğu sanat aktiviteleri, sinemalar ve cafeler, kahvehaneler olmuştur. Bunların kısıtlamalar çerçevesinde iptal edilmeleri ve kapatılmalarının sosyalleşme üzerinde ve tabii ki insanların ruh hallerinde de olumsuzlukları yanında getirmiştir.

Toplumsal dönüşümlerin ilk izlerini sanatın mizah alanında görmek sürpriz olmaz. Mecburi evde kalma durumları, çeşitli kısıtlamalar, sosyalleşme yerlerinin kapatılması gibi kararlar tüm alanlarda etkisini gösterirken mizahta da kendini göstermiştir. Covid- 19 toplumları çok boyutlu olarak etkilerken mizahta bu etkileri en kolay şekilde dile getiren bir araçtır. Mizah anlatılması ve açıklanması zor olan kavramlardan bir tanesidir. Yüzyıllardır farklı farklı tanımlanan mizah Martin tarafından "psikolojide, eğlenceli, komik veya saçma şekilde uyumsuz fikirlerin, durumların veya olayların alg1sıyla, ifadesiyle veya takdiriyle ilişkili oldukça geniş bir olgunun anlatımı" olarak tanımlanırken Recepoğlu daha dar ve pozitif anlam içeren bir tanım yapmış ve mizahi olumlu düşünceler oluşturan bir kavram olarak ele almıştır (akt: Büyükyılmaz, 2018, s.5). Klein ise mizahın kişileri iyileştirici yönüne dikkat çekmiş ve mizahın olumsuz olayları olumlu hale dönüştürücü bir gücü olduğunu bir örnek üzerinde öne sürmüştür. Klein'ın verdiği örnek tanınmış komedyenler üzerine yapılmış bir çalışma üzerinedir. Bu çalışmada görülmüştür ki, ünlü komedyenlerin çoğunun hayatı acı ve ıstıraplar içinde geçmiş olmasına rağmen, bunları başarılı kılan unsurun kendile rinle ve yaşadıklarınla dalga geçme ve gülme olduğu ortaya çıkmıştır (Klein,1989, s.19). Yaşadığımız dünyada sosyal gerçeklik kişiler üzerinde ağır baskılar oluşturur. Sosyal hayatta bireylerin durmaksızın kimlik inşası yorucu bir eylemdir ve birey yoruculuktan bir an olsun siyrilmak ve gevşemek ister. Mizahin en önemli gücü gündelik hayatın zihinlerimize vermiş olduğu yorgunluğu almasindandır (Eagleton, 2019, s. 35- 36). 
Gülmek ile mizah arasındaki ilişkiyi kısaca tanımlayacak olursak mizah bir yaratma durumu iken gülme ise bu yaratı durumuna fiziksel olarak tepki verme durumudur. Gülme çok boyutlu bir eylemdir ve birçok etkene bağımlı olarak gelişir ve mizah gülmeyi yaratan durumlardan sadece birisidir. Mizahı Bayraktar şu şekilde tanımlar:

1. Mizah toplumsal bir olgudur.

2. Mizahın içinde mutlaka bir komik durum, gülünçlük vardır.

3. Mizah zeka ve algulamayla ilgilidir.

4. Mizahta alışlmadık, uyumsuz bir durumun var olması çok önemlidir.

5. Mizah kimine göre sanat, kimine göre ise edebiyattır, bazılar ise mizahın felsefe olduğu görüşündedirler.

6. Toplumun yaşadı̆̆ı coğrafya, iklim, din, dil ve adetlerin farklılığına göre mizah anlayışı da tamamen değişir (Özgüleş, 2020, s. 12-13).

Mizah ve gülme birbirini tamamlayan iki anahtar kavramdır ve bu iki kavram eğlence endüstrisinin ana hatlarını oluştururlar. Mizah beden üzerinde gülme olarak adlandırılan tepkiye neden olurken zihinsel anlamda yaratmış olduğu tepki ise "dışlama, dikkat çekme, kınama, alay etme, statü," gibi işlevlerdir. Mizahın kültürel bir kodu vardır ve kültürden kültüre farklılık gösterir. Dolayısıyla kültürleri anlama bağlamında mizah önemli analiz etme araçlarından birisidir (Eker, 2014, s. 6).

Mizah sadece kişiler arasında gelişen bir durum değildir, bazı durumlarda ise kişiler üstü bir duruma eğrilmektedir. Mizahın gücü siyasi iktidarlar tarafından da farklı olarak kullanılmaktadır. Yönetilen bir durumda olan, yani siyasi erkin dışında olan ve onu kullanmayanlar mizahı, yönetenin eleştirilmesi, küçük düşürülmesi ve hatta inceden dalga geçilmesi bağlamında teşvik etmektedirler. Yönetilenlerin yönetenler safına geçtiklerinde ise daha önce siyasi erkle dalga geçilmesini onaylayan mizahı bu sefer yasaklama yoluna gitmektedirler ve mizahı anarşist bir eylem olarak tanımlamaktadırlar. Bu duruma en iyi örnek Öngören'in İttihatçılarla Abdülhamid arasındaki anlattı̆ı ilişkidir. Siyasi iktidarı ele almadan önce dönemlerde İttihat ve Terakki Partisi'nin üyeleri Abdülhamid'in karikatürlerle dalga geçilmesini onaylarken, Abdülhamid'in devrilip iktidarı kendilerinin ele almasından sonra mizaha sansür uygulamaları bu duruma en iyi örnektir (akt: Eker, 2014, s. 7).

Günümüzde teknolojinin bireylerin hizmetine sunulması gündelik hayatta pek çok şeyin değişimine neden olmuştur. Değişikliklerin belki de en 
önemlisi kullanıcıların ağlar üzerinde Web 2.0'ın sayesinde sosyal paylaşım sitelerinde içerik oluşturmaları gelmektedir. Web 2.0 tabanlı yeni medya klasik medyanın tam tersini oluşturmaktadır. Bu oluşan yeni medya diğerine göre daha özgürlükçü ve demokrat olmasının sebepleri 'ötekine' kendini ifade etme şansı vermesi ve klasik medyanın tersine kullanıcıların iletişimin kaynağı olması ve içerik oluşturmalarıdır (Uybadın\& Mumcu, 2013, s.85). Web 2.0 teknolojisi kullanıcıların içerik oluşturması nedeniyle katılım kültürü oluşturmuştur. Tüketmekten çok yeni medyada üreten durumuna gelen kullanıcılar kendi serüvenlerini mizahi bir dilde aktararak yeni bir alan açmışlardır. Oluşturulan mizahi içerikler tek sesliği ortadan kaldırmış ve diğer kullanıcıların da oluşturulan bu mizahi içeriklere dahil edilmesi katılımcı kültürü oluşturan yeni bir söylem oluşturmuştur (Kırık\& Saltık, 2017, s.100).

Kullanıcıların içerik oluşturmada en mizahi olanlardan bir tanesi de 'caps'ler gelmektedir. Tanım olarak Yıldırım caps'i şu şekilde tanımlar:"Caps en basit anlamiyla kapak yapmak anlamına gelmektedir. Argoda "kapak yapmak" tabiri sık kullanılan bir tabirdir. Özellikle karşıdaki insanı bozmak ve bağlamına göre oldukça uygun bir söz söylemek anlamına gelebilmektedir." (Yıldırım, 2020, s.16). Capsler, sosyal medya ortamında paylaşılan gündelik olayların alaycı ve eğlenceli bir biçimde ifade ediliş tarzıdır. Son dönem tüm dünyada yaygın olarak kullanılan capsler aslında kısaca bir olayın, kişinin ya da şeyin ekran görüntüsünün alındıktan sonra elde edilen görüntünün fotoshop üzerinden işlem yapılarak sunumu hazır hale getirilmesidir (Aktaş, 2016, s.5- 6). Fakat görselin tek başına olması caps için yeterli değildir. Bununla birlikte, elde edilen görselin üzerine uygun düşen bir metnin işlenmesi gerekmektedir (Karataş\& Binark, 2016, s.437). Tekrin'e göre capsler hep bir değişim içindedir ve herkes capsler üzerinde değişiklik yaparak onu tekrar düzenleyip yenileyebilir. Her yenileme bir yeniden yaratma sürecidir (akt: Karataş\& Binark, 2016, s.437). Capsler eğlence ve dalga geçmek üzerine kurulu olduğundan dolayı spordan siyasete, sanattan, edebiyata ve kişilere kadar tüm alanlarda kendine bir konu bulabilmektedir.

\section{Göstergebilim}

Göstergebilim tanım olarak karışık bir yapı içermektedir. Guiraud, göstergebilimi "diller, düzgüler, belirtgeler, vb. gibi gösterge dizelerini inceleyen bir bilimdir" diye tanımlar. Saussure ise göstergebilimi "göstergelerin toplum içindeki yaşamını inceleyecek bilim" olarak tanımlar (Guiraud, 2016, s.17). 
Göstergebilimin en önemli kavramı adından geldiği gibi göstergelerdir. Dizge birimleri de gösterge olarak adlandırılır. Dizge birimleri insanların birbirleriyle iletişim kurmak amacıyla geliştirmiş oldukları dilden, vücut hareketlerine, moda, reklamdan mimari tarzlara kadar geniş bir yelpazeye uzanan her türlü bildirişimlerin bütünlüklü halinin tanımlanmasıdır. Bu bütünlük aslında anlamlı olan ve insanlarda çağrışım uyandıran göstergelerdir. K1sacası, Rıfat'ın tanımıyla "Kendi dışında bir şeyi temsil eden ve dolayısıyla bu temsil ettiği şeyin yerini alabilecek nitelikte olan her çeşit biçim, nesne, olgu, vb." gösterge olarak tanımlanır (Rifat, 2008, s.115).

Her ne kadar batıda göstergebilim kavramı bu bilimin kurucusu olan Saussure tarafından toplumsal işlevi ön plana çıkarılıp vurgulanırken, Pierce ise mantıksal işlevini vurgulasa da, göstergebilimde bu iki yaklaşım arasında derin bağlar vardır. Günümüz dünyasında semiotik ile semioloji aynı alan içinde değerlendirilmektedir. Kavramın içeriğinin derin olması ortak bir noktada buluşmayı zorlamaktadır. Bu karmaşadan uzak durmayı tercih edenler dil dışı iletişim dizgelerini takip ederken, Saussure ve onun takipçileri gösterge ve düzgü kavramını toplumsal içerik oluşturan moda, düğün, tören, gelenek gibi kültürel kodlar içine yerleştirerek onları daha anlaşılır hale getirirler (Guiraud, 2016, s.20).

Saussure ve Pierce' in temelini attı̆̆ göstergebilim 1960'll yıllardan itibaren değişime uğramıştır. Yeni dönem temsilcilerinden biri olan Barthes göstergeler arasına kültürü de eklemiştir. Çünkü kültür göstergeleri değiştirebilmekte ve farklı anlamlar yükleyebilmektedir (Rifat, 2008, s.139-140). Barthes'i Saussaure'den farklı kılan şey göstergenin önemini reddetmemesine rağmen göstergenin tek başına anlamlı olmadığını söylemesidir. Her ne olursa olsun dili anlamlı kılan şeyin göstergeler ve göstergelerin dile çevrilmesi olduğunu öne sürer. Göstergeler ve dil içiçe olan kavramlardır ve biri olmadan diğeri olmaz fakat göstergenin dile çevrilmesi önemlidir (Bircan, 2015, s.19). Barthes dil ve gösterge ile ilgili olan görüşünü göstergebilim İlkeleri adlı eserinde göstergebilimi'nin ilkelerin tek amacının "dilbilime dayanarak çözümsel kavramlar ortaya koymak" olarak tanımlar (Bircan, 2015, s.19).

Barthes etrafımızda sözcüklerden tutun da olgulara kadar her şeyin görünürlüğün arkasında gizli kalan, çözülüp anlatılmayı bekleyen yapılar bütünü olduğunu savunur. Bu gizli kalmış görünmeyen, açığa çıkarılması gereken bu yapılar aslında ideolojik söylemlerin birer parçalarıdır (Karaduman, 2017, s.37). 
Barthes'e göre, düzanlam, herkes tarafından kabul gören, nesnel durum ve içerikler için kullanılan anlamdır. Yoruma gerek kalmayan evrensel bir durumken, yananlam ise daha çok sübjektif olan, kişiden kişiye değişen anlamlandırma ilişkisidir. Bu anlamlandırma ilişkisi de metin içinde saklıdır. Barthes yananlam ve düzanlamı üniforma örneği ile daha net olarak açıklamaktadır. Düzanlam olarak bir generalin üniformasını değerlendirecek olursak sadece bir elbisedir. Oysa yananlam olarak o sadece bir elbise değildir artık, üzerindeki ilişik bulunan yıldızlar, "güç", "otorite", "hiyerarşi" gibi şeyleri zihnimizde çağrıştırır. Yananlam değerlendirilmesi çok yönlü bir durumdur. Çünkü göstergeler kültürden kültüre farklılık gösterirler. Bir kültürde bir göstergenin çağrıştırdıkları ile diğer kültürrde oluşturduğu çağrışım farklılık gösterir. Olan ya da oluşturulan göstergenin doğru anlamda ve istenildiği gibi yorumlanması isteniyorsa eğer göstergenin verildiği kültür çok iyi tanınmalıdır (akt: Çakı, 2018, s.77). Karaduman'a göre, yananlam," ideolojik anlatının yapısal çözümlenmesinde anlam düzeyi olarak var olur" (Karaduman, 2017, s.37).

\section{Yöntem}

\section{Araştırmanın Deseni}

Bu çalışmanın amacı Covid -19'un neden olduğu pandemi döneminin caps kültürü üzerinden irdelemektir. Araştırmanın temel problemi ise Covid19 'un yaratmış olduğu olumsuz yaşam ve düşünce tarzlarının capsler üzerinden gösterilmesidir. Çalışmada yöntem olarak 2020 Nisan ile Kasım ayları arasında örneklemi temsil edecek sosyal medya üzerinden yayılan capslerin 8 caps seçilerek analizi yapılmıştır. Şeyler ve görüntüler her zaman oldukları gibi ya da göründükleri gibi değildir. Özellikle sanatsal yaratı, caps, karikatür gibi görsel özelliği ön planda tutulan sanatlarda görünenin arkasında duran ya da ima edilenler önem arz etmektedir. Bu çalışmada Barthes'in yananlam - düz anlam bağlamında göstergebilimsel yöntemi kullanılmıştır.

\section{Çalışma Etiği}

Çalışmanın Yürütülmesinde etik ilkelere dikkat edilmiştir. Çalışma yürütülürken atıflar etiğe uygun olarak gösterilmiştir. Bunlarla birlikte iThenticate intihal programında taranmıştır. 


\section{Evren ve Örneklem}

Bu araştırmanın hedef çalışma grubunu sosyal medyada Covid- 19 döneminin işlendiği bazı capsler oluşturmaktadır. Çalışmada kullanılan capslerden altı tanesi, pinterest.com sitesinden, iki tanesi de haberpop sitesinden corona ile bağlantılı olarak toplumsal sıkıntıları işleyenler arasından amaçlı örneklem metodunun tipik durum örneklemi seçilmştir.

\section{Bulgular}

Bu kısımda internet üzerinden seçilen capslerin içerik çözümlemelerine yer verilmiştir.

Caps 1.

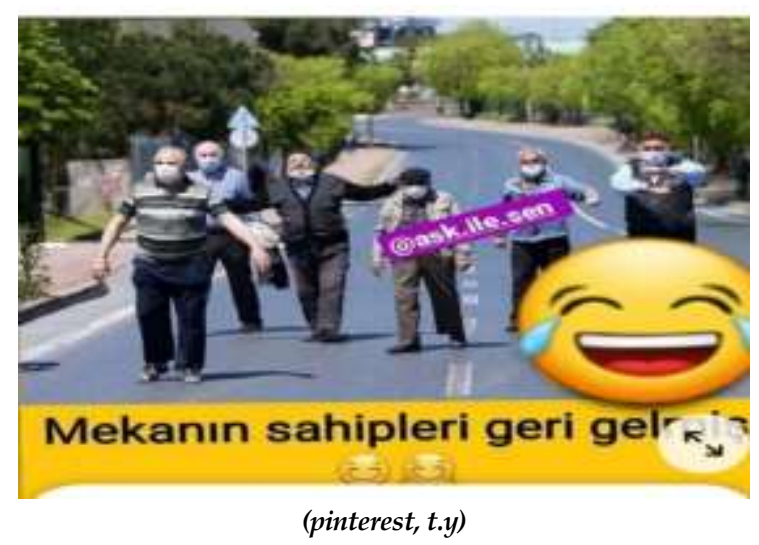

Gösterge: Sokakta yürüyen bir gurup yaşlı insan

Gösteren: Görselde sokağa çıkma yasağının 65 yaş üstü kişiler için kısıtlı olarak kaldırıldığı bir günde, yüzlerinde maske ile egzersiz yaparak yolun ortasında yürüyen bir grup yaşlı insan görülmekte. Fotoğrafın altında "mekânın sahipleri geri gelmiş" metni ve gülen surat emojileri yer almakta

Gösterilen: Neşe, mutluluk, yürüyüss, yaşlılar, ağaçlar, boş cadde

Analiz: Görselin düz anlamına bakıldığında sokağa çıkma yasağının kaldırıldığı bir zaman diliminde, 65 yaş üstü 6 kişinin caddenin ortasında egzersiz yaparak yürüdüğü görülmektedir. Yananlam olarak mekânın onlara ait olduğunu göstermek için bir metafor olarak kullanılan, "mekânın sahipleri geri geldi" metni yer almakta. Pandemi döneminde yaşlıların risk grubunda yer 
almasından dolayı ev kısıtlamasına maruz kalan en önemli grubu oluşturmaktadır. Yaşlıların ev kısıtlaması sonucu hem sosyalleşme yönünden hem de hareketsizlik sebebiyle sağlık sorunları ortaya çıkmıştır. "Mekânın sahipleri geri geldi" metaforu bu yüzden yananlam olarak içinde çift anlam barındırır. İlki caddeyi kapatacak şekilde neden egzersiz yaparken ellerini iki yana açarak yürüyüş yaptıklarını açıklarken, diğeri ise sosyalleşmekten dolayı mutluluğu temsil eder. Kullanılan gülen surat emojileri ise yan anlamın mizah yönünü desteklemektedir.

\section{Caps II:}

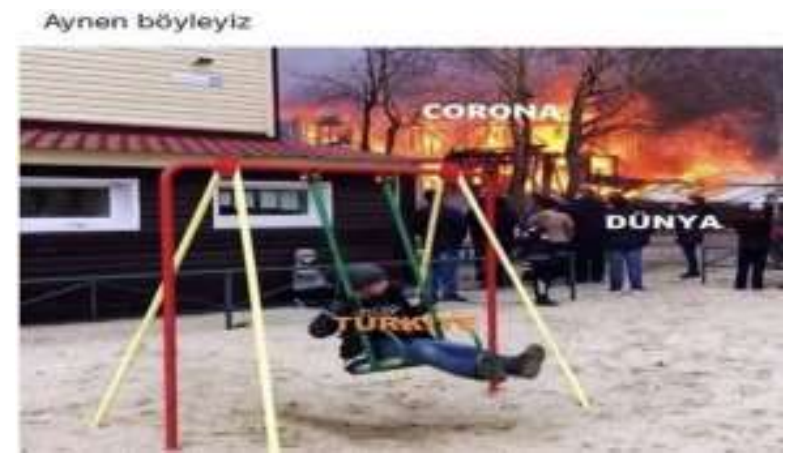

(Pinterest, t.y)

Gösterge: Bir gurup insanın yangın izlediği alanda sallanan bir çocuk

Gösteren: Sallanan bir çocuk, arka tarafta yanan bir ev, yanan evi izleyen kalabalık bir insan gurubu, yerde karla kaplı bir zemin

Gösterilen: Corona pandemisi, Türkiye, Dünya, kaygısızlık

Analiz: Capsin düz anlamına bakıldığında corona olarak nitelendirilen bir yangın ve yangını izleyen dünya yazısıyla belirtilen bir gurup insan söz konusudur. Bu kalabalık insan gurubunun arkasında ve bahçenin ön tarafinda sallanan ve sallanırken de kalabalığı izleyen Türkiye olarak nitelendirilen bir çocuk. Yan anlama incelendiğinde Covid-19'dan bahsedildiği anlaşılmaktadır. Covid- 19 yangını tüm dünyayı kasıp kavururken insanlar çaresizlik içinde yangını izlemekte ve yangına müdahale edememektedir. Bahçenin ön tarafında Türkiye olarak nitelendirilen çocukla capsin esas amacı ortaya çımaktadır. Capsin vurgusu, Türkiye' nin yangına tıpkı bir çocuk gibi duyarsız olduğunu, çocuksu bir şekilde keyfine devam ettiğinden ama diğer taraftan 
da merakından dolayı sallanırken başını yangın yerine çevirerek olayı anlamaya çalıştı̆ını ve sadece izlediğini göstermektedir. Caps'de tüm dünya yangınla uğraşırken Türkiye'ye henüz yangının ulaşmadığı ve Türkiye'nin olayı anlamaya çalıştı̆̆ gözlemlenmektedir.

Caps III.

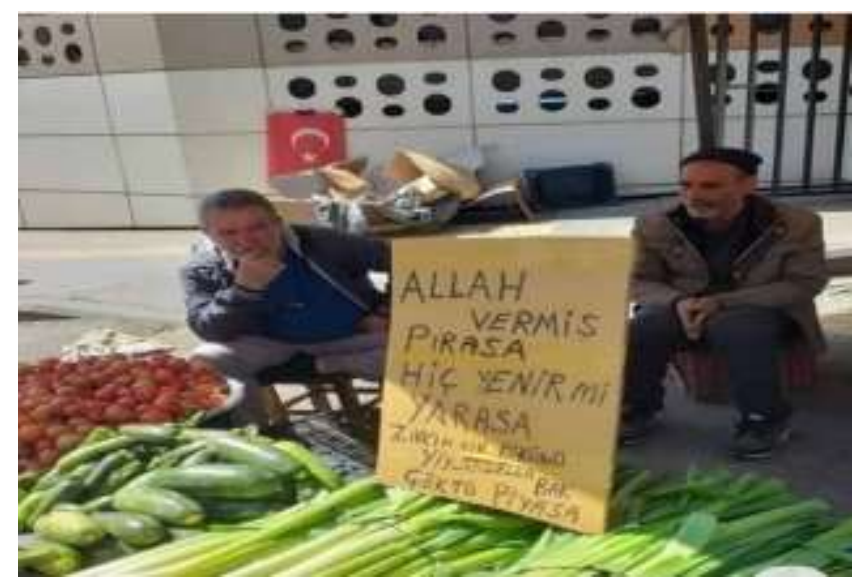

(Pinterest, t.y)

Gösterge: Pazarda sebze satan iki kişi

Gösteren: Pazar yeri, pazarcılar, pırasa ve diğer sebzeler, pırasaların üzerinde yazı olan bir karton

Gösterilen: Mutsuzluk, telaş, kızınlık, maddi zorluk

Analiz: Caps de düz anlam olarak bakıldığında Pazar yerinde Pırasa ve diğer sebzeleri satan iki pazarc ve Pırasanın üzerine "ALLAH VERMISŞ PİRASA HIÇ YENİR MI YARASA ZIKKIMIN KÖKÜNÜ YIYYESELER BAK ÇÖKTÜ PIYASA" diye bir karton üzerine yazılmış bir tepki yazısı vardır. Oysa esas anlam yan anlamda gizlidir. Yananlam analiz edildiğinde bu kişilerin ne amaçla böyle bir şey yazdıkları anlaşılmaktadır. Bilindiği gibi Covid-19 pandemisinin çıkış sebebi Çin'in Wuhan kentinde bulunan hayvan pazarında satılan yarasalardan yapılmış çorbadan bulaştığ 1 öne sürülmüştür. Bu yarasa çorbalarının sonucunda ilk etapta Wuhan'da ortaya çıkan yeni tip virüs sonra tüm Çin ve dünyaya yayılmıştır. Önlenemeyen ve bir türlü çözümü bulunamayan Covid- 19 hızlı yayılmış ve ölümlere neden olması sonucu hastaneler dolmuştur. Bunun sonucunda hükümetlerin kısıtlamalara gitmesi sonucu 
ekonomik olarak tüm toplumlar büyük hasar görmüş ve piyasalar çökme noktasına gelmiştir. Capsde yer alan pankart üzerindeki yazının yananlam çözümlemesi Covid- 19'un bu durumuna bir tepkidir ve sıradan, doğal besinlerin tüketilmesi gerekirken neden yarasa gibi bir hayvanın yendiği eleştirilirken diğer taraftan da bu yeme alışkanlığının insanlara ekonomik zarar verdiğini anlatmakta ve dolaylı olarak kültürel bir yaklaşım izlenerek Çin kültürünün yeme alışkanlığı ethnocentric olarak kritize edilmektedir.

Caps IV.

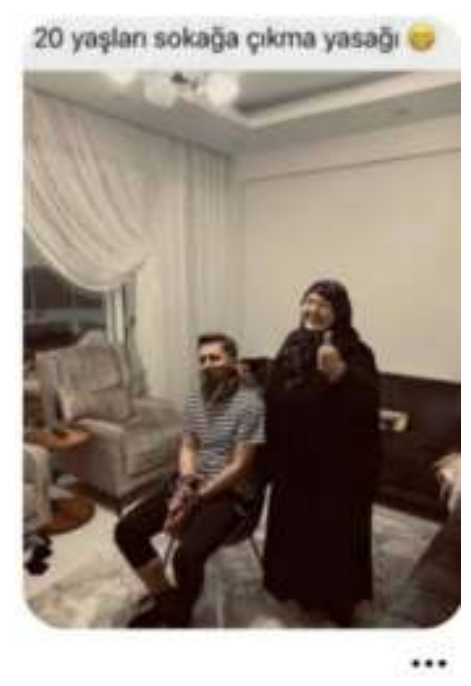

(Pinterest, t.y)

Gösterge: Büyük bir salon, mobilyalar, ağzı, elleri ve ayakları bağlı bir genç ve yaşlı bir kadın

Gösteren: Eli, ayağı ve ağzı bağlı sandalyede oturan bir genç, mobilya dolu bir salon ve yaşlı bir kadın

Gösterilen: Covid- 19'dan dolayı gencin zorla evde tutulması, kadının parmakla uyarısı, zapt edilememe durumu

Analiz: Capsin düzanlamı salonun ortasında bir sandalyeye iplerle annesi olduğu düşünülen bir kadın tarafından elleri bağlanmış ve ağzı da bir bezle kapatılmış bir genç ve "sakın yapmayın ya da uzak durun" anlamına gelen bir işaret yapan gencin annesinin işareti gösterilmektedir. Yananlam da ise 
caps'in dayanağının Covid- 19 pandemisinin ilk göstergelerinin Türkiye'de çıkmasının ardından İçişleri bakanlığının aldığı bir karar sonucu çalışan gençlerin dışında kalan diğer gurup gençlerin kısıtlamaya tabi tutularak belirli saatlerde dışarıya çıkmalarına izin verilmesi ile ilgilidir. Verilmek istenen mesaj ise gençlerin evde zorla tutulduğudur.

Caps $V$.

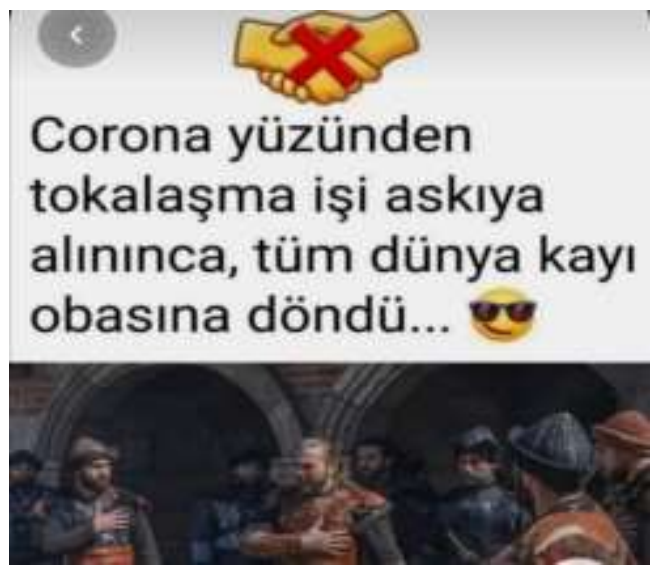

(Pinterest, t.y)

Gösterge: Selam veren savaşçllar

Gösteren: Ellerini göğüslerinin üstüne koymuş savaşçllar, üstte bir yazı ve gözlüklü adam emojisi

Gösterilen: Kayı boyunun selamı, corona'dan dolayı selamlaşmanın değiş̧mesi

Analiz: Düzanlam olarak fotoyu yorumlamaya çalışırsak Kayı boyunun televizyonda gösterilen hikâyesinin bir enstantanesi alınmış olarak görülmektedir. Burada Kayı boyundakilerin selamlaşması gösterilmektedir. Fotonun hemen sol üst kısmına da "Corona yüzünden tokalaşma işi askıya alınınca, tüm dünya kayı obasına döndü..." diye bir yazı eklenmiş ve bu yazı bir tane de güneş gözlüklü adam emojisi eklenmiştir. Yananlam olarak da Türkiye'de Covid- 19 yaygınlaşmaya başlayınca tokalaşmanın virüs yayma da doğrudan rolü olduğundan dolayı insanlar tokalaşmaktan vazgeçmiş ve saygı - selam anlamımda aynı fotoda gösterildiği gibi sağ ellerini sol göğsünün üstüne koyarak karşısındakilerini selamlamıştır. Karşısındakiler de selamını gördüm 
ve selam veriyorum anlamında aynı hareketleri yapmaktadırlar. Bir taraftan Covid- 19 korkusunun insanların alışkanlıklarının üzerinde derin değişiklikler oluşturduğu ima edilirken diğer taraftan da bu selamlaşma şekliyle de alttan alta dalga geçilmekte ve memleketin artık Kayı boyu gibi olduğunu söylenerek duruma mizahi bir anlam katılmaktadır.

Caps VI

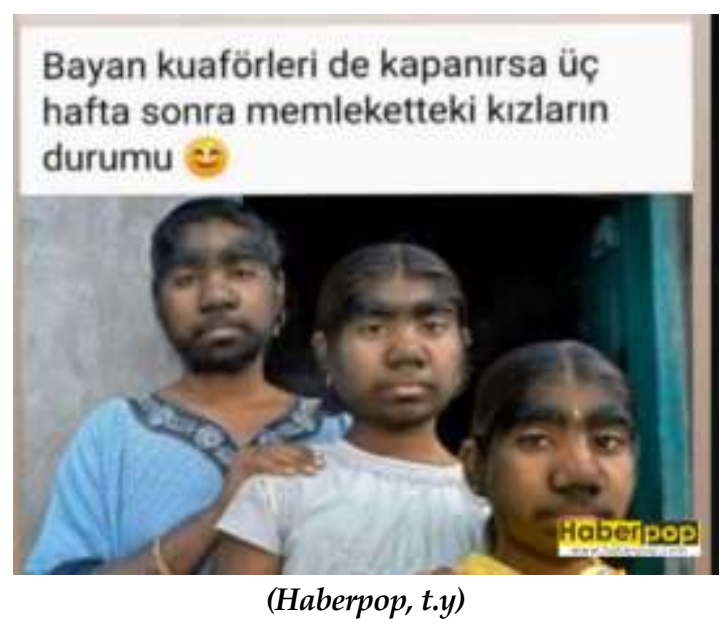

Gösterge: Üç tane genç kız

Gösteren: Üç tane yüzleri abartılmış bir şekilde kıllarla kaplı genç kız, sol üstte yazı ve emoji

Gösterilen: Dalga geçme, eğlenme, eril bakış açısı, küçümseme Analiz: Düzanlam olarak fotoda yüzleri kıllarla örtülü durumda olan Türkiye dışından bir foto paylaşımı yapılmıştır. Fotoda 3 tane genç kız boy sıralamasına göre dizilmiş olarak görülmektedir. Genç kızların yüzleri özelliklede kaşları ve bıyık bırakılan alan kıllarla doludur. Fotonun hemen sol üstüne de "Bayan kuaförleri de kapanırsa üç hafta sonra memleketteki kızların durumu" diye bir yazı eklenmiş ve yazının hemen bitimine de gülen adam emojisi iliştirilmiştir. Yananlam da ise Covid- 19 salgının Türkiye'de ortaya çıkması ve yayılması sonucu hükümet tarafından bir takım kısıtlamalar ve yaptırımlar devreye sokulmuştur. Yaptırımların gün ve gün artması sonucu sıranın berber ve kuaförlere de geleceğinin beklentisi caps de mizahi bir anlatıyla fakat daha çok kadınları aşağılayıcı bir dille ortaya çıkmıştır. Kısıtla- 
maların özellikle kadın kuaförlere doğru yayılması durumunda karşılaşılacak durumun Türkiye de de fotodakinden farklı olmayacağ 1 ima edilmiştir. Fotodaki diğer yananlam ise eril bakışın net bir ifadesi olarak karşımıza çıkmaktadır. Türkiye'de kadın oldukça sık kuaförlere giderek bakım yaptıklarını, eğer gitmezlerse üç hafta da bu hale gelir der gibidir ve aslında bir küçümseme de söz konusudur. Diğer taraftan da yine eril bakış açısıyla verilen bir mesaj vardır: kadın kendisine bakmalı, güzelliğe ve estetiğe önem vermeil denilerek kadını bedeni eril bakış üzerinden inşa etme çabası söz konusudur. Caps de asıl vurgulanmak istenen eril bakış açısıdır ve bu bakış Akçora'nın anlatımıyla şöyle özetlemektedir:

“...kadın arzu nesnesi bağlaminda 'gözleyen ve gözlenen' olarak yer alırken, geleneksel edilgen kadın imgelerini pekiştirmekte, kadın salt bedene ve güzelliğe indirgeyerek sömürülmesini meşrulaştırmaktadır." (Parsa ve Akçora, 2016, s.37).

Caps VII

\section{Yaşı inbar hattı ALO 153 ... 65 yaş üstü insanları sokakta görürseniz arayın.}

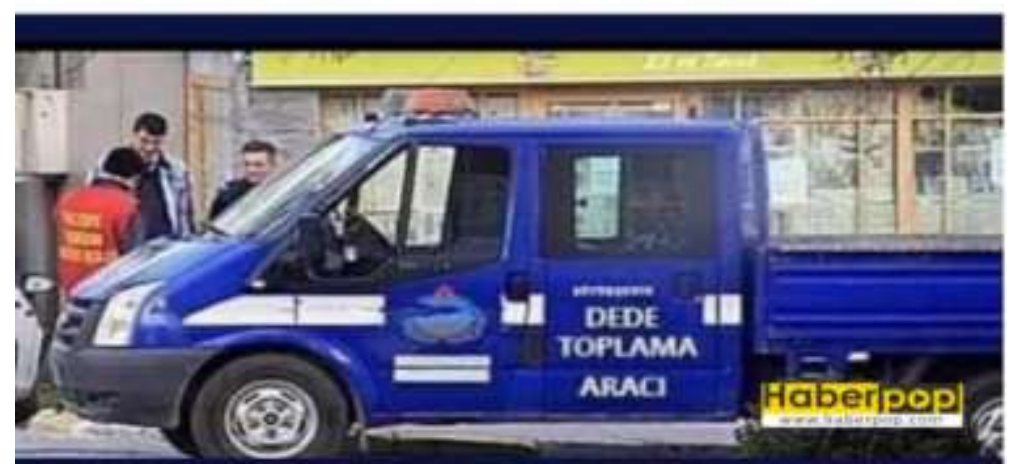

(Pinterest, t.y)

Gösterge: Zabita arabası

Gösteren: Zabıta arabası, arka fonda 3 kişi, "Dede Toplama Aracı" ifadesi

Gösterilen: Yaşlıların yasağı delmesi, dedelerin dikkatsizliği ve umursamazlığı, yaşlılara karşı önyargı 
Analiz: Düzanlam olarak fotoda bir zabıta arabası ve görevli birisinin iki kişiyle konuşması görülmektedir. Zabıta arabasının üzerinde de “ DEDE TOPLAMA ARACI" yazısı dikkat çekmektedir. Yananlam ise yaşlılara pandemi sürecinde yapılan kötü muamele ve önyargılar içermektedir. Covid- 19 sürecinde getirilen ilk kısıtlamaların 65 yaş ve üstüne getirilmesi toplumda pandeminin bu yaş grubu tarafından dağıtıldığı gibi saçma bir önyargı oluşmasına neden olmuştur. Aslında kısıtlamanın esas amacı yaşlıların bağışıklık sistemlerinin zayıf olduğu düşüncesi ve tüm dünyada bu grubun korumaya alınmasından kaynaklanmaktadır. Fakat ülkemizde yasağın ilk dönemlerinde yaşlılar tarafından tam uyulmaması sonucu pek çok yaşlı dişarlarda dolaşmaya devam etmişlerdir. Bu durum da kendi hayatlarını riske atmak olduğundan dolayı yaptırımı olan önlemler alınmıştır. Fakat televizyonlarda sıklıkla parklarda ve sokaklarda gezinen yaşlıların gösterilmesi kamuoyunda yaşlılara karşı bir önyargı oluşturmuş ve sanki her şeyin sorumlusu onlarmış gibi bir algı ortaya çıkmıştır. Sokaklarda dolaşan yaşlıların gerek vatandaşlar gerekse kolluk güçleri tarafından evlerine gitmeleri için uyarılmaları istenmeyen sonuçları da beraberinde getirmiştir.

Bilim insanları Türkiye' de pandemi öncesinde de yaşlılara karşı bir ayrımcılık yapıldığını ve yapılan saha çalışmalarının da bu öngörüyü desteklediğini söylemektedirler. Türkiye' de yapılan çalışmalarda yaşlılara karşı yapılan ayrımcllı̆ın kamusal tüm alanlarda olduğunu ve bu ayrımcılık oranlarının \%15 gibi rakamlara tekabül ettiklerini söylemektedirler. Pandemiyle bu durum daha da kötüleşmiştir. Doç. Dr. Özgür Arun bu ayrımcılık ilişkisini kaygıyla şu şekilde ifade eder:

Salgından sonra ayrımcılığın daha da arttığını biliyor, hep birlikte izliyoruz. Bizim en büyük endişemiz sokağa çıkma yasağıyla birlikte ayrımcı tutumların davranışa dönüşmesiydi. Bu değişimin ve ardından çatışmanın geleceğine dair endişemiz vardı. Son günlerde yaşadığımız şey, yaşlılara karşı ayrımcı tutumların davranışa dönüşmesidir. (Arun'dan aktaran Gökırmaklı, 2020).

Pandeminin ilk döneminde yaşlıların evlere götürülmesi için belediyeler tarafından yapılan Dede Toplama Aracı aslında ülkenin yaşadığı trajikomik durumu gözler önüne sermektedir. Fotoya herhangi bir yazı eklemesi yapılmamış olmasına rağmen caps özellikleri taşıması da fotoyu ilginç hale getirmiştir. Çünkü arabanın üzerinde bulunan" Dede Toplama Yazısı" fotoyu ister istemez capse dönüştürmüştür. 


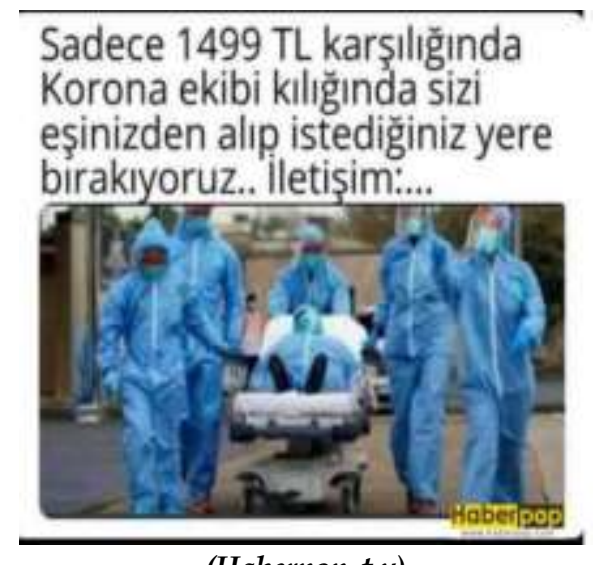

(Haberpop, t.y)

Gösterge: Beş kişinin bir kişiyi sedye ile taşıması

Gösteren: Beş tane sağlık çalışanı hijyen koşulları içerisinde bir hastayı tekerlekli sedye ile taşıması ve "Sadece 1499 TL karşılığında sizi Korona ekibi kılığında eşinizden alıp istediğiniz yere bırakıyoruz...İletişim...." ibaresi

Gösterilen: Erkek şiddeti, pandemiden dolayı çiftlerin evde tüm gün kalması, evde kalmaktan kaynaklanan gerginlik.

Analiz: Düz anlam olarak beş tane sağlık çalışanın bir hastayı taşıdı̆̆ı görülmektedir. Dikkat çeken detay ise sağlık çalışanlarının tamamıyla kapanmış ve hijyen tulumlarla olmalarıdır. Bu pandeminin getirmiş olduğu yeni bir durumdur. Yananlam olarak caps değerlendirildiğinde pandeminin neden olduğu kısıtlama sonucu çiftlerin büyük zamanları evde geçirmeleri sonucu şiddet olaylarında gözle görülebilir bir artış yaşanmıştır. Şiddet olayların artışı sadece Türkiye' de değil tüm dünyada görülmüştür. Erkek şiddetinin nedenleri arasında erkeğin işini kaybetmesinden ev içi iş bölümüne kadar farklı alanlarda çıkan çatışmalar sonucudur. Erkek şiddeti sadece Türkiye'de değil Avrupa ve A.B.D'de artış göstermiştir. Belirtilen raporlarda erkek şiddetinden dolayı şiddete maruz kalan kadınlar korkudan dolayı yardım talebinde dahi bulunamamıştır. Fransa' da erkek şiddetinden dolayı kadın sığınma evleri dolmuş ve bunun sonucunsa hükümet ilave tedbirler çerçevesinde bazı otelleri de sığınma evine döndürülmesi için yardım istemiştir. Raporlara göre, "Fransa, Avustralya, Arjantin ve Singapur'da yüzde 25 ile 33 oranında arttı. Türkiye'deki artış yüzde 27.8 olarak raporlandı." (Büyüktaş, 2020). 


\section{Tartışma ve sonuç}

Bu çalışmada Covid- 19'ın neden olduğu toplumsal sıkıntılar mizahi çerçevede capsler ile anlatılmaya ve analiz edilmeye çalışılmışır. Covid- 19 toplumların İspanyol gribinden sonra gördüğü en kaygı yaratıcı pandemi olarak tarihteki yerini almıştır. Covid-19'u toplumların gözünde önemli ve ciddi k1lan şey bulaşın hızlı bir şekilde yayılması ve tedavi sürecinin bir türlü başlatılmamasıdır.

Sürecin zorluluğu hükümetlerin önlem almasına neden olmuş ve insanlar tüm dünyada kısıtlamalar sonucu büyük sıkıntılarla karşı karşıya kalmıştır. Pandemi bir yandan ekonomik yapıyı alt üst etmiş diğer taraftan da insanların evlerde kalmasına neden olmuştur. Toplumsal sorunlara neden olan pandemi en iyi ifadesini mizahta bulmuştur. Mizah bir yandan pandeminin neden olduğu sorunları kritize ederken bir yandan da insanları eğlendirerek onları karamsar dünyalarından çıkarmaya çalışmıştır.

Mizahın bir kolu olan capsler özellikle sosyal medyanın aktif olarak kullanımından sonra ortaya çıkan güldürü ve düşündürücü mesajları olan teks eklenmiş fotolar olarak ön plana çıkmıştır. Caps mizah kültürünün bir parçası olmasının yanı sıra teknolojik olarak yenilenmiş bir güldürü - düşünme durumunu ortaya çıkarırken, diğer taraftan da yapısı gereği kültürel ve demokratik bir tepki aracıdır. Kahya' ya göre, capslerin farklı bireyler tarafından sürekli şekilde gündemde kalıp tekrar ve tekrar üretilmesi yeni toplumsal algıların oluşumunda etkili olmuştur (Kahya, 2018: 1028). Çalışma Covid19'un neden olduğu toplumsal sorunların capsler aracilığıyla insanlara nasıl iletildiği üzerinedir. Seçilen capsler pandemi sürecinin toplum içindeki izdüşümleridir. 


\section{EXTENDED ABSTRACT}

\section{Analysis of Caps Created During The Covid-19 Pandemic \\ Onur Bayrakçı \\ Bandırma Onyedi Eylül University}

Covid-19 emerged in Wuhan, China, in early 2020. As in all societies Covidpandemic has had an effect in Turkey. As a result of this effect, the government had to take some measures. This restriction of Covid-19 has caused extraordinary changes in all areas of society. Restrictions have been applied in all areas, from age groups to tradesmen's opening hours. Therefore, some social consequences and reactions have emerged.

The fact that the group over 65 and under 18 are the most important victims of the restriction, the closure of certain parts of the tradesmen and the curfews naturally created a change. As always, the changes caused by Covid19 first found their answer in humor.

Human beings want to communicate with others by its nature. Communication, just like societies, has always undergone a change throughout the ages and has been shaped according to the necessity of the age. Humor has been one of the important instruments in communication. While humor makes people laugh from one side, it also leads them to think through a number of messages from the other side. The social dimension of humor is too important to be thrown aside. The lack of democracy in some societies has carried the development of humor even further. Humor is an art, which is the way of expressing untold or unexplained.

Caps is a form of humor and web 2.0 has created the caps culture. The Web 2.0 feature is online. In the previous period, the web system was 1.0, that is, communication was a one-sided system that was satisfied with what the server offered. In Web 2.0, this online state of users means interactivity, that is, mutual communication of users. That is, this interactive state, on the one hand, brought users against each other and enabled them to communicate with each other, on the other hand, it caused the emergence of caps culture.

Caps culture is a culture that emerged as a result of interactive use. In this culture, first, all users either write text on a particular photo or make some 
editing on the photo. Later, the photo is transferred from user to user, so the photo has been enriched in the web environment in the process of circulation, that is, a culture of participation has emerged. Caps, which are a branch of humor, came to the fore as text photos with funny and thought-provoking messages, especially after active use of social media. In addition to being a part of the humor culture, Caps is a technologically renewed comedy - while revealing the state of thinking, it is also inherently a cultural and democratic reaction tool.

In this study, the restrictions and lockdown that occurred as a result of the Covid-19 pandemic and the situations experienced as a result of these were discussed. The aim of this study is to analyze the problems caused by the pandemic through caps.

Caps selected as samples were analyzed through Barthes' denotation and connotation dimensions. Semiotics is actually the act of approaching things in a more careful way. The essence of their approach to things as a philosophy is that they are not what they should be, they have a number of messages both in language and in appearance, and these messages should be read and understood correctly. So the main thing to see is that it is below what is visible. Given this approach, Barthes developed two perspectives when evaluating things. First there is the analysis of denotation. Denotation is the state of conveying or describing things as they are or as they appear. Second connotation is the situation that needs to be analyzed, demonstrated and uncovered. While the meaning is the reflection of the object in the human, the connotation is the different state of perception. If we will explain it based on the famous example of Barthes: "The general's dress is just a dress, as a meaning, whereas as a connotation indicates authority and hierarchy."

As sample, the typical sample condition of the purposeful sample was chosen in the study. In the selection of this method, the boundaries of the selected caps and each sample were chosen among the examples that best describe the subject in the context of Covid-19. The selected caps are examples of caps that reflect the situations in society within the framework of the limitations taken in the Covid-19 period. Each analysis in caps shows the negative effects of the Covid-19 period on society. 


\section{Kaynakça / References}

Aktaş, Ö. (2016). Bir iletişim yöntemi olarak caps / memes. İnönü Üniversitesi Sanat ve Tasarm Dergisi, 6(14), 1- 14.

Barthes, R. (2018). Göstergebilimsel serüven . (Çev. M. Rifat, ve S. Rifat ). (9. Basım). İstanbul: Yapı Kredi Yayınları.

Bircan, U. (2015, Güz). Roland Barthes ve göstergebilim. Sosyal Bilimler Araştırma Dergisi, 26, 17- 41.

Büyüktaş, O. (2020). Pandemi döneminde erkek şiddeti arttı, kadınların çaresizliği de... https://www.cumhuriyet.com.tr/haber/pandemi-doneminde-erkek-siddeti-artti-kadinlarin-caresizligi-de-1749861 adresinden 17 kasım 2020 tarihinde alındı

Büyükyılmaz, O. (2018). İş hayatında mizah kullanımı. Bursa: Ekin Yayınclık .

Çakı, C. (2018). Roland Barthes'ın göstergebilimsel çözümlemesi ile Nazi propagandasında engelliler. SDÜ IFADE, 1(2), 66- 91.

Eagleton, T. (2019). Mizah. ( Çev., M. Pekdemir). İstanbul: Ayrıntı Yayınları.

Eker, G. Ö. (2014). İnsan kültür mizah. (2.basım). Ankara: Grafiker Yayınları.

Gökırmaklı, I. (2020, Nisan 2). Yaşlılara karşı nefret dili revaçta, çünkü yaşlanmaktan korkuyoruz. https://journo.com.tr/koronavirus-yaslilar-ayrimcilik adresinden 15 Ekim 2020 tarihinde alındı

Guiraud, P. (2016). Göstergebilim. (Çev.M. Yalçı). (3 Basım). İstanbul: Ankara: İmge kitabevi

Haberpop. (2020). En komik coronavirüs galerisi: videolar, fotograflar, capsler, tweetler, gifler. https://haberpop.com/en-komik-coronavirus-galerisi-videolar-fotograflar-capsler-tweetler-gifler/ adresinden 05 Ekim 2020 tarihinde alınd 1

Kahya, Y. (2018). Bir iletişim aracı olarak mizah: Sosyal medyada spor temalı 'caps' kültürü. AVRASYA Uluslararası Araştırmalar Dergisi, 6(15), 10201030.

Karaduman, S. (2017). Eleştirel söylem çözümlemesinin eleştirel haber araştırmalarına katkısı ve sunduğu perspektif. Maltepe Üniversitesi İletişim Fakültesi Dergisi, 4(2), 31- 46.

Karataş, Ş., ve Binark, M. (2016). Yeni medyada yaratıc kültür: Troller ve ürünleri 'caps'ler. TRT akademi, 1(2), 426- 448.

Kırık, A. M., ve Satılık, R. (2017). Sosyal medyanın dijital mizahı: İnternet meme/caps. Atatürk İletişim Dergis, 12, 99- 118. 
Klein, A. (1989). Mizahın iyileştirici gücü. (Çev. G. Işık, Dü., ve S. Karayusuf,) İstanbul: Epsilon Yayınevi.

Özgüleş, B. (2020). Sağllk yönetimi ve mizah. Ankara: Nobel Yayıncılık.

A. F. Parsa ve Akçora, E. (2016). Ses Dergisinde eril bakış altında nesneleştirilen kadın imgeleri. Ege Üniversitesi Basımevi

Pinterest.com. (2020). Corona caps. https://tr.pinterest.com/eyllakilli/corona-caps/ adresinden 24 Ekim tarihinde alınd.

Rifat, M. (2008). XX. yüzyılda dilbilim ve göstergebilim kuramları. (4. Basım). İstanbul: Yapı Kredi Yayınları.

Uybadın, A., ve Mumcu, N. (2013). Diyalog 2.0: Yeni medyanın “öteki ile ben” diyaloguna katkıları üzerine hermeneutik bir yaklaşım. Yeni medya çalışmaları kuram, yöntem, uygulama ve siyasa I.Ulusal Kongresi içinde (s. 82- 92). Kocaeli: Alternatif Bilişim. https://ekitap.alternatifbilisim.org/pdf/ymk1.pdf adresinden 09 Kasım 2020 tarihinde alındı

Yıldırım, O. (2020). Katılımcı kültürü eleştirmek: Dr. Younan Nowzaradan ile ilgili caps, tweet ve ekşi sözlük entrylerinin değerlendirilmesi. Kritik İletişim Çalışmaları Dergisi, 01, 13- 22.

\section{Kaynakça Bilgisi / Citation Information}

Bayrakçı, O. (2021). Covid-19 pandemi sürecinde oluşturulan capslerin analizi. OPUS-Uluslararası Toplum Araştırmaları Dergisi, 17(Pandemi Özel Sayıs1), 3501-3521. DOI: 10.26466/opus.853718 